\title{
Casa Poli
}

Tomé, Chile

Era difícil resistir la tentación de alcanzar el borde, de sentir la caída, estando frente a un acantilado. Teníamos una sensación de vértigo un poco morbosa. Retirada del borde, según advertencia estructural, confinamos la operación en una pieza compacta que ocupa el único sitio menos escarpado. Aquello nos obligaba a elevar el suelo hasta recuperar al menos dos cosas: una era la sensación de un podio natural rodeado de nada y la otra era esa lectura morbosa y en primer plano al pie del acantilado.

Si en vez de techo decidimos dejar una terraza que ocuparía toda su superficie, el interior debía moldearse de acuerdo a condiciones puntuales: su base es una plataforma quebrada en tres niveles que bajan con la topografía; el vacío de triple al.ura que ocupa la plataforma más baja (orientado al noroeste) pretende contener la dimensión vertical del acantilado, acusando la experiencia aérea del mar; las dos habitaciones del segundo piso se desplazan (en sentido este - oeste) para conseguir condiciones visuales equivalentes.

Dado que el programa debía alternar un centro cultural con una casa de vacaciones, nos enfrentamos ante una vocación contradictoria: mediar entre una dimensión muy pública y otra más íntima e informal. O sea, a hacer algo medio monumental y medio doméstico, sin que una calidad le pesara a la otra.

Por ello, decidimos no nombrar los recintos por sus funciones y más bien dejarlos sin nombre y sin función, como meras salas más o menos interconectadas, para luego llevar todo el programa de servicio hacia el perímetro, hacia un muro exageradamente grueso, un espesor habitable, que actuaría como fuelle.

Dentro de este perímetro vaciado quedan la cocina, las circulaciones verticales, los baños, armarios y una serie de balcones interiores. Eventualmente, todos los muebles y objetos domésticos pueden guardarse dentro de este perímetro, liberando el espacio para múltiples actividades.

Mauricio Pezo, arquitecto
Algunas obras que valoramos comparten cierta indeterminación; ella las hace más flexibles y retarda su obsolescencia, pero no proviene de una indiferenci a los actos que en ellas ocurren. Por el contrario, y paradójicamente, se trata de una cualidad generada en la atención cuidadosa al programa, entendido como un germen capaz de desarrollarse y cambiar.

Palabras clave: Arquitectura - Chile, Pezo von Ellrichshausen, segunda vivienda, hormigón armado, pabellón polifuncional.
Some works that we value share a certain indefiniteness: this makes them more flexible and retards their obsolescence, but that does not arise from indifference to the acts that take place within them. On the contrary, and paradoxically, it concerns a quality generated by careful attention to the program, understood to be a germ that is capable of developing and changing.

Palabras clave: Arquitectura - Chile, Pezo von Ellrichshausen, vacation home, Palabras clave: Arquitectura - Chile, Pezo vo
reinforced concrete, multifunctional pavilion.
Intervenir un paisaje idílico. Perturbarlo. Esta es una condición que parecía inevitable. Siempre recordamos las sanciones de Loos (Loos, 1910). Las llevamos a cuestas. Por eso estoy de acuerdo con Pezo cuando dice que "esta nueva construcción no podría ser menos que una severa figura a medio trabar entre la tierra y el mar. Una suerte de refutación de los contemporáneos discursos que diluyen la distinción entre natural y artificial".

Una serie de relaciones de continuidad dejan percibir una relativa temporalidad, una presencia simultánea, entre los diferentes espacios interiores. Casi como en un cuadro cubista, tal como dijera Rowe, las piezas se transparentan fenomenológicamente. El interior fluye continuamente hasta sus limitantes perimetrales, transversal, sagital y verticalmente. Es una masa vaciada. La percepción de la totalidad del espacio interior, más que recinto, se presenta como un campo continuo, un paisaje interior. Este paisaje interior se alterna y complementa con la presencia del paisaje natural exterior. La luz natural distorsiona, segrega, invierte, el contrapunto visual que hay entre un paisaje y otro. A pesar de la robustez de sus estructuras, la sensación de levedad e ingravidez del espacio percibido es ostensible.

Sin duda la obra obliga a un movimiento ritualizado. La disposición de circulaciones dentro del espesor habitable establece, imperativamente, la ocupación del perímetro, de los límites de este confinamiento. Con ello estamos forzados insistentemente a mirar hacia afuera, a dejar de ver la propia obra, a evadirnos del interior, a deshabitar la arquitectura. Aquí la obra desaparece, se niega a sí misma, se desborda su medida antropométrica en la extensión de los acantilados. Como en todo ritual, se establece una relación forzada, repetitiva, tensa, controlada. En esta correspondencia repetitiva es en donde deberíamos encontrar el verdadero programa arquitectónico de la obra.

Eduardo Meissner Centro Cultural Casa Poli
La situación apartada de la obra condicionó nuestra operación; trabajar con tecnología arcaica y mano de obra carente de especialización. Abordar la construcción desde esta realidad precaria, tan imperfecta como inacabada, o desde el horno de ladrillos y el peón para usar las imágenes de Martínez Estrada, más que una apología del menor esfuerzo, suponía una denuncia de un estado de cosas (Martínez Estrada, 1942).

La casa se construiría en siete meses. Uno para tareas de instalaciones previas y seis meses para los seis estratos de vaciado de hormigón. Que la casa se haya construido en más de un año y medio, además de un pésimo negocio, es una confirmación de nuestras primeras sospechas.

Los camiones descargaban a $150 \mathrm{~m}$ de la faena, en una cota $30 \mathrm{~m}$ más alta. Todos los materiales se bajaron a pie. La mezcla se hizo con dos pequeñas betoneras y se trasladaba en cuatro carretillas. El agua se sacaba de un pozo que gracias a los bomberos pudo ser recargado un par de veces durante el verano.

Durante la construcción trabajaron más de 30 personas, entre carpinteros, enfierradores y jornales. Aunque nunca más de 6 a la vez. Muchos interrumpían sus contratos para dedicarse a su labores de labrado o pesca artesanal. Ninguno leía planos.

Terminada la obra gruesa la casa se veía igual que ahora. Casi no tiene terminaciones. Un par de detalles de ventanas, que todavía estamos tratando de ajustar. Usamos las mismas tablas maltratadas de los moldajes para revestir los muros interiores que tienen contacto con el exterior. También para construir unas correderas que sirven como puertas de clósets y postigos que cubren las ventanas cuando la casa se abandona.

En los muros de hormigón quedaron las huellas de las tablas de moldajes; los leves desaplomes, descalces y descuadres no dejan de cristalizar algo de nuestro drama por salir del paso. Esto no dista mucho de aquella definición que hace Gyhka del paisaje; una huella cicatrizada de un conflicto de fuerzas naturales (Gyhka, 1950).

Sofía von Ellrichshausen, arquitecta, como constructora
Bibliografía: Gyhka, Mathila; Estética de las proporciones en la naturaleza y en las artes. Original de 1950. Editorial Poseidón, Barcelona, 1983. / Loos, Adolf; "Arquitectura". En Ornamento y delito y otros escritos. Original de 1910. Editorial Gustavo Gili, Barcelona, 1980. / Martínez Estrada, Ezequiel; Radiografía de la pampa. Original de 1942. Editorial Losada, Buenos Aires, 2001. / AA.VV.; Ochenta y nueve, noventa y uno. El proyecto Casa Poli. Ediciones CASAPOLI, Concepción, 2005. 


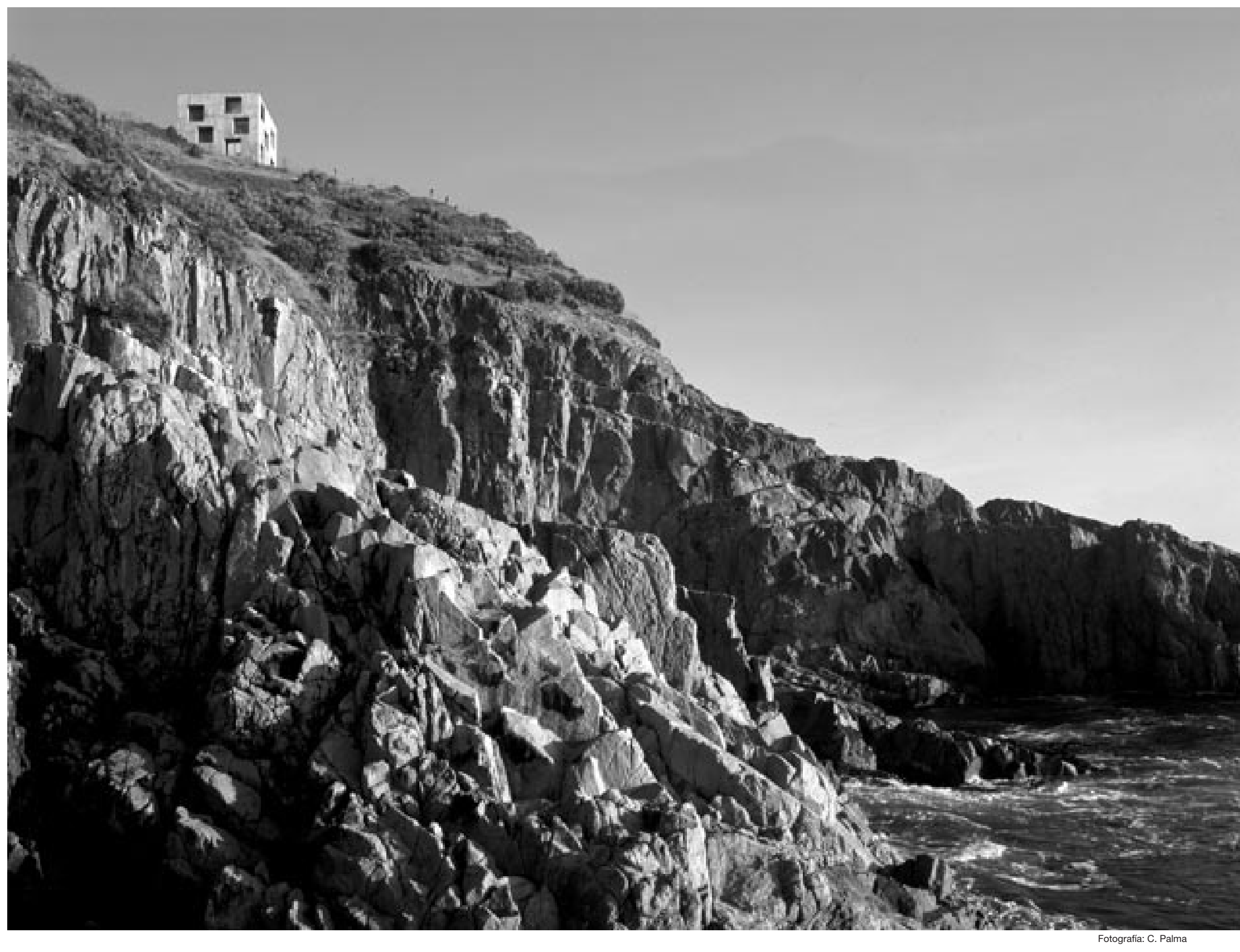




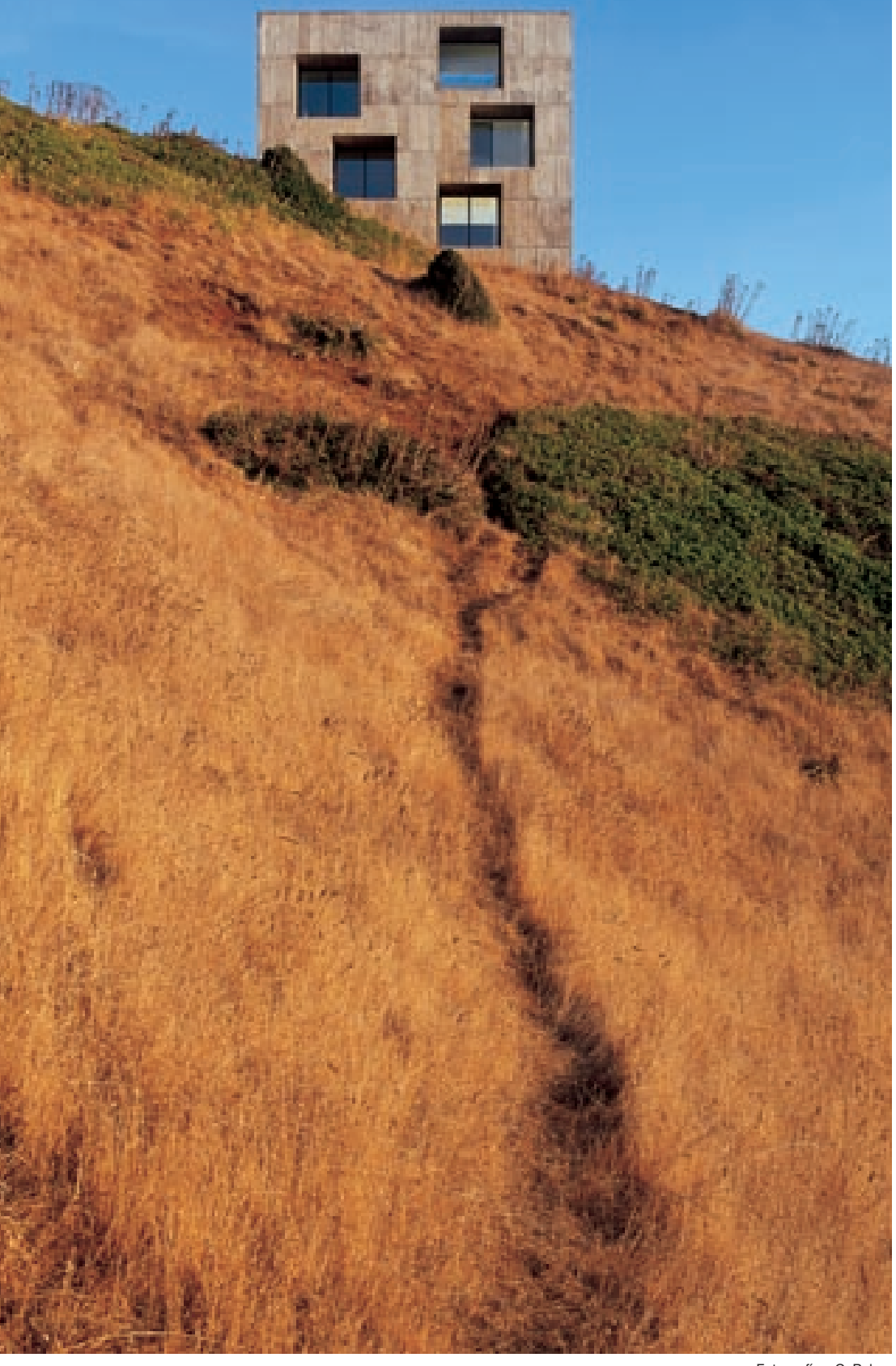

Fotografias: C. Palm
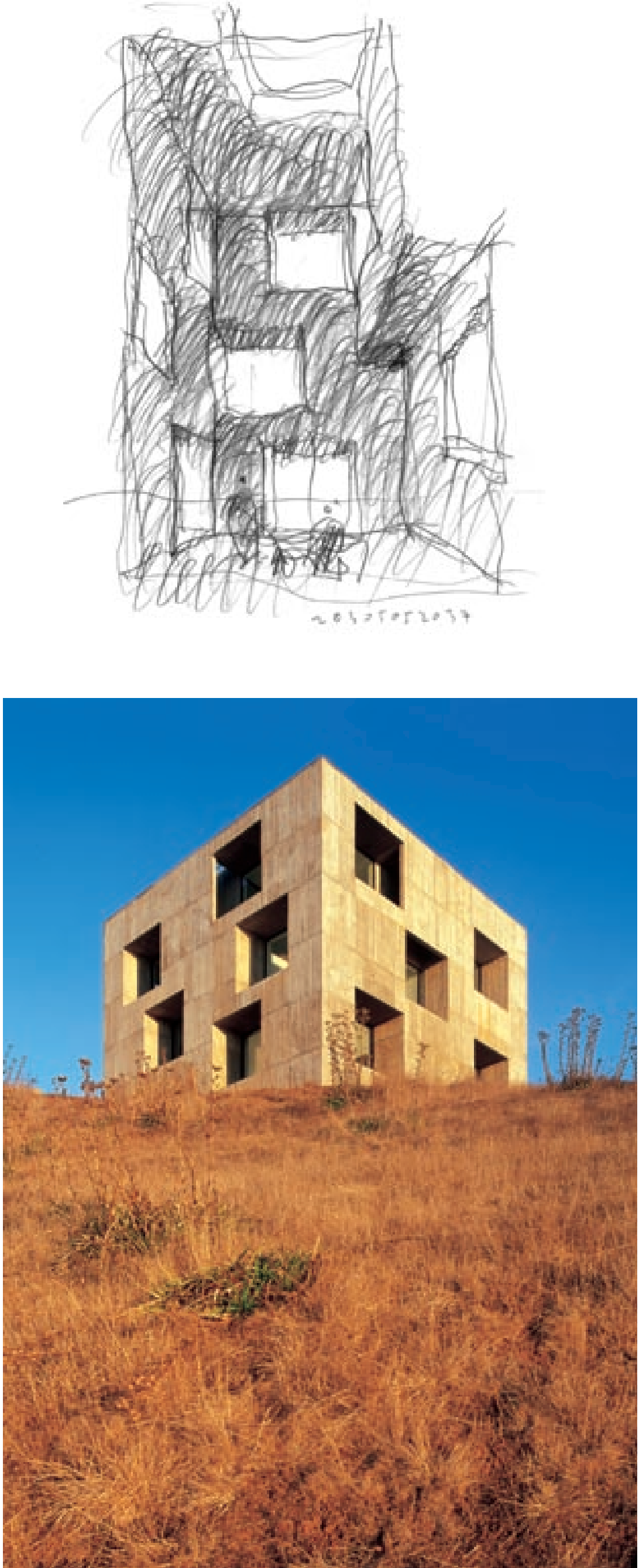

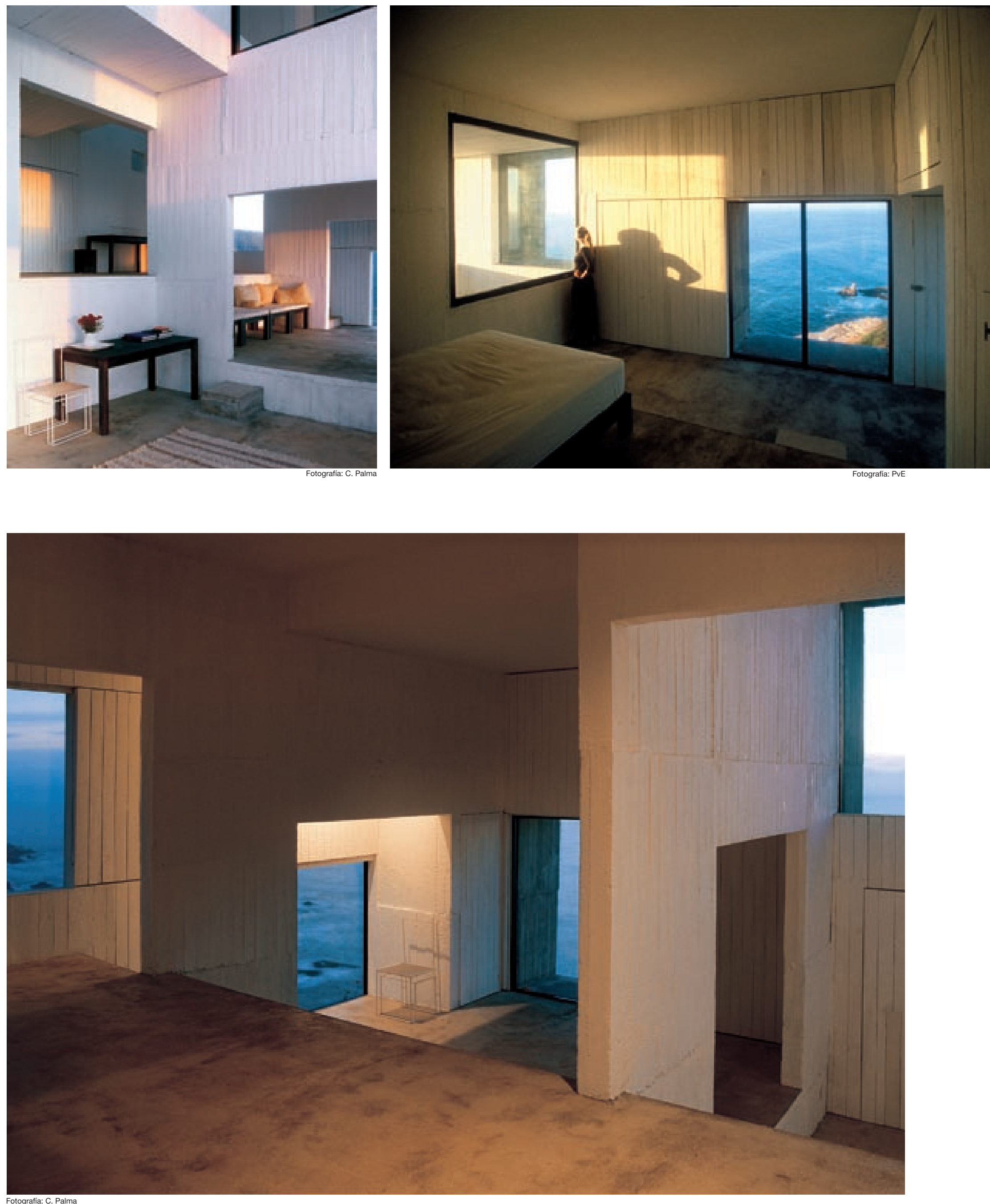


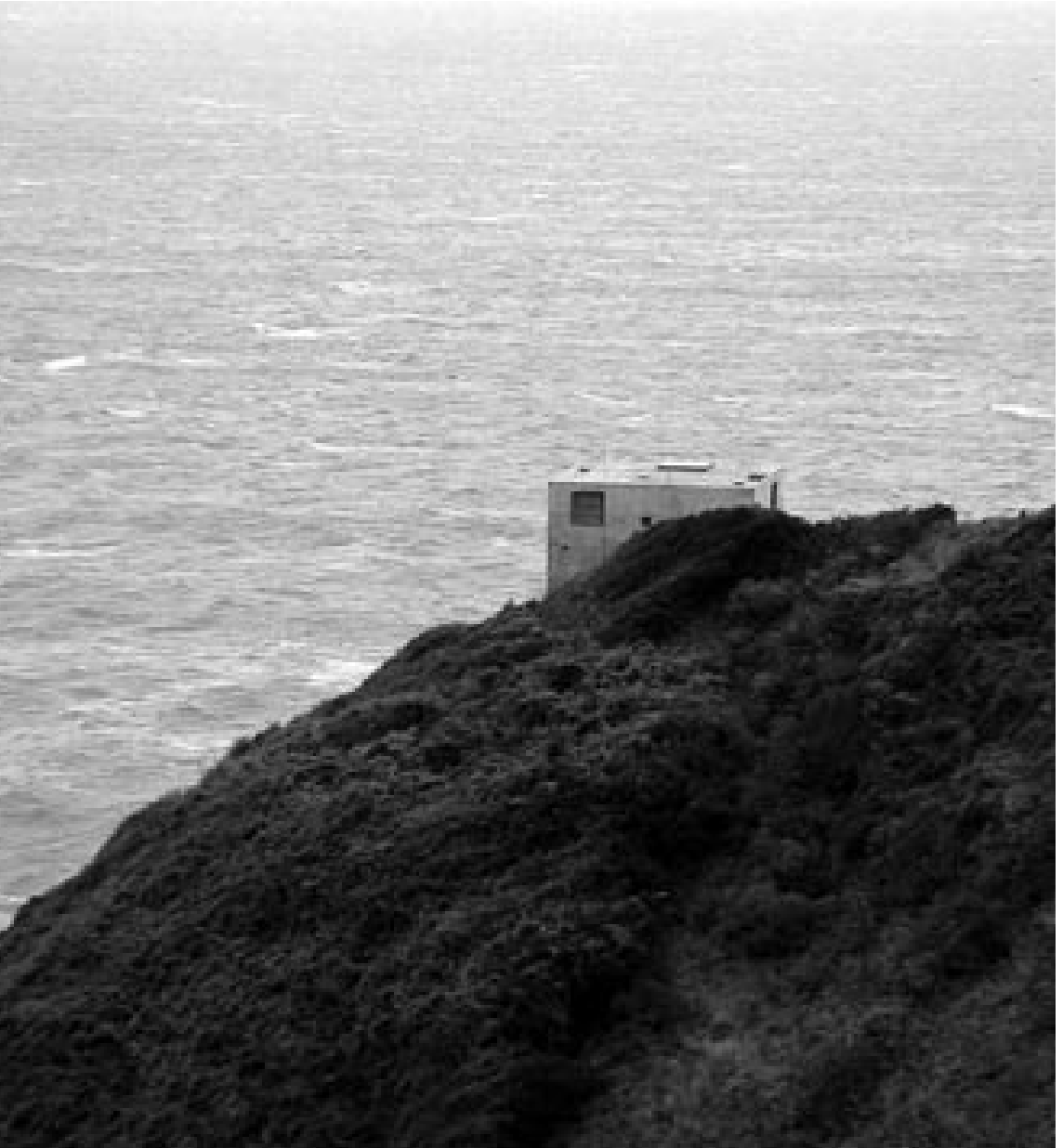

Fotografía: PvE

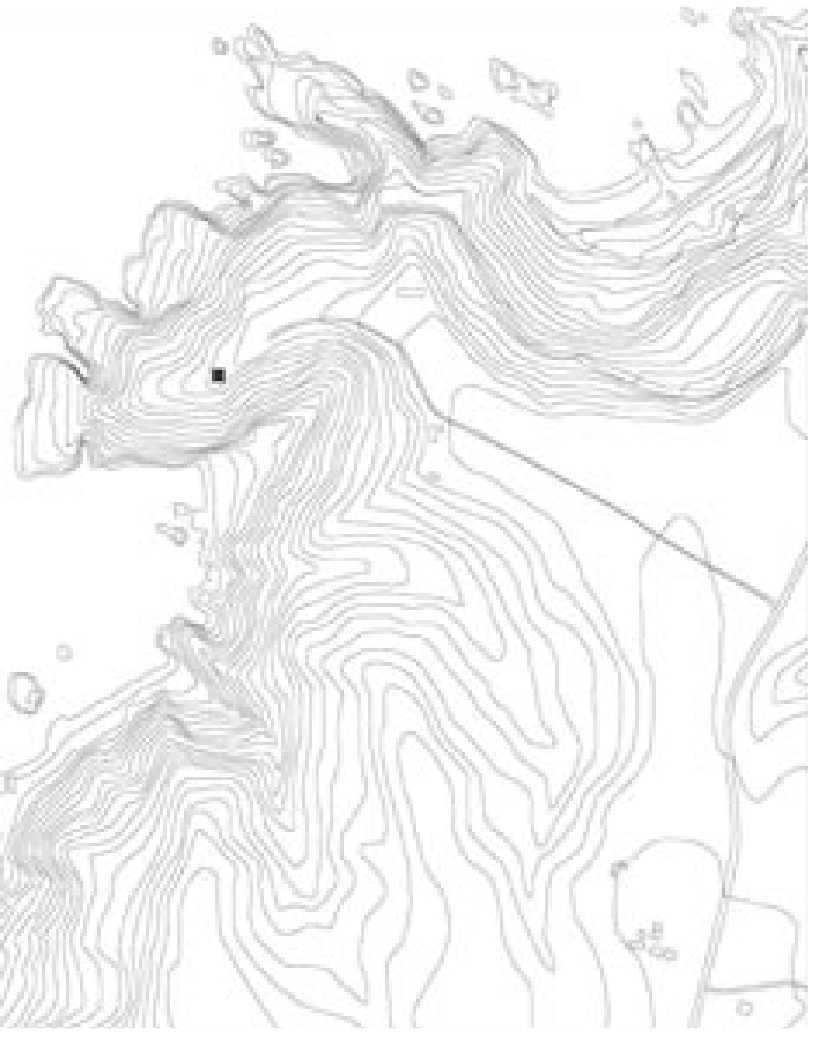

Planta emplazamiento (I)
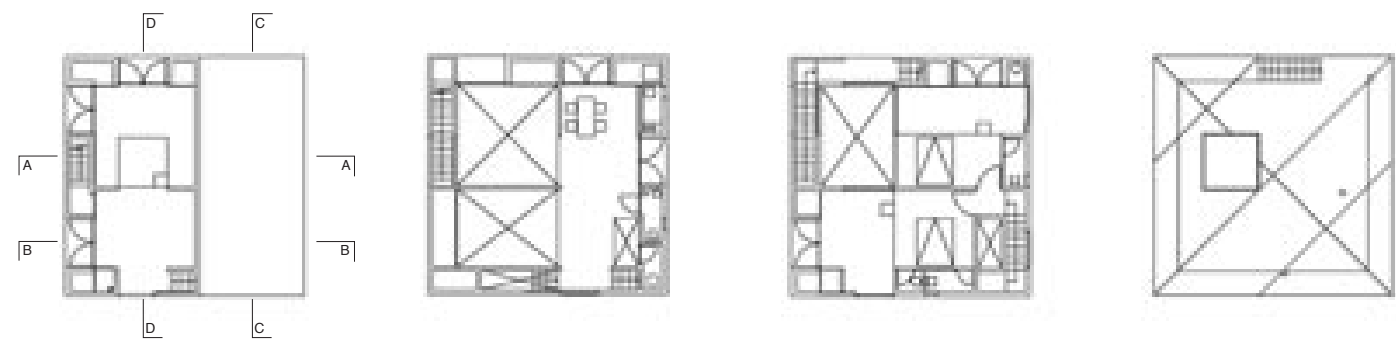

Nivel +- $0.00 \quad$ E / 1:250

Nivel + 1.50

Nivel +3.00

Nivel + 7.60
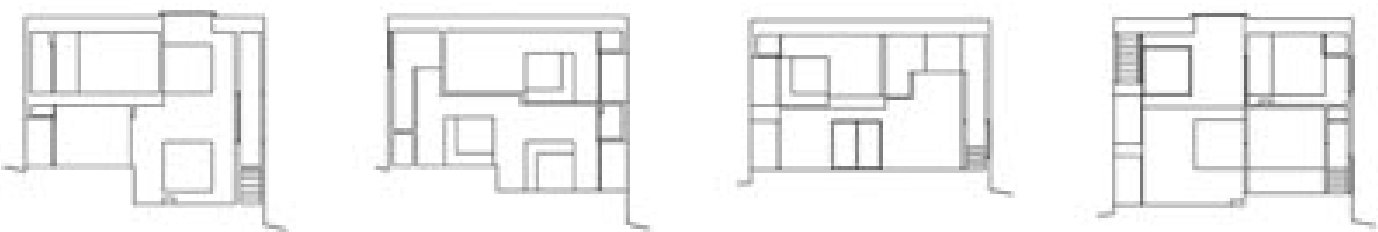

AA

BB

CC

DD
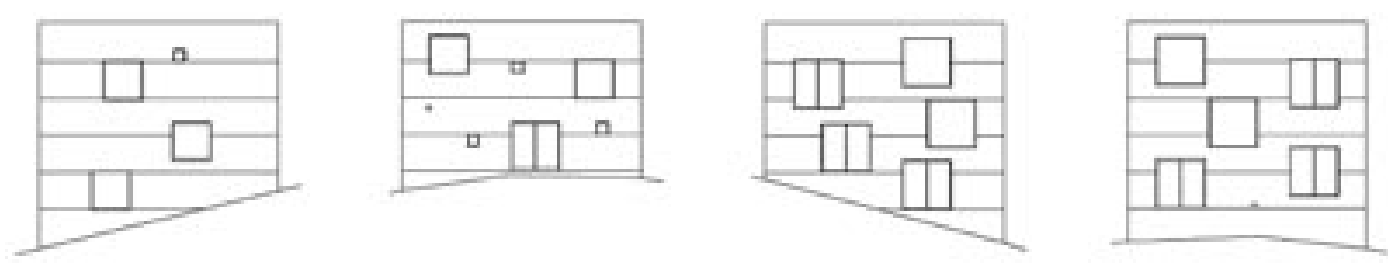

Norte

Poniente 


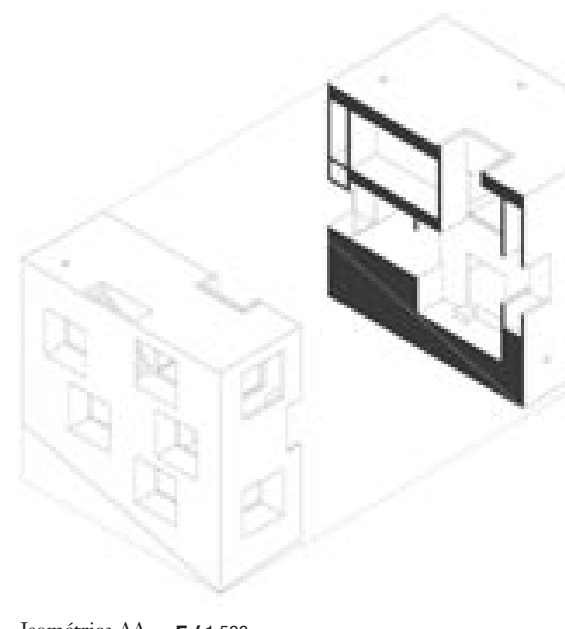

Isométrica AA E/1:500

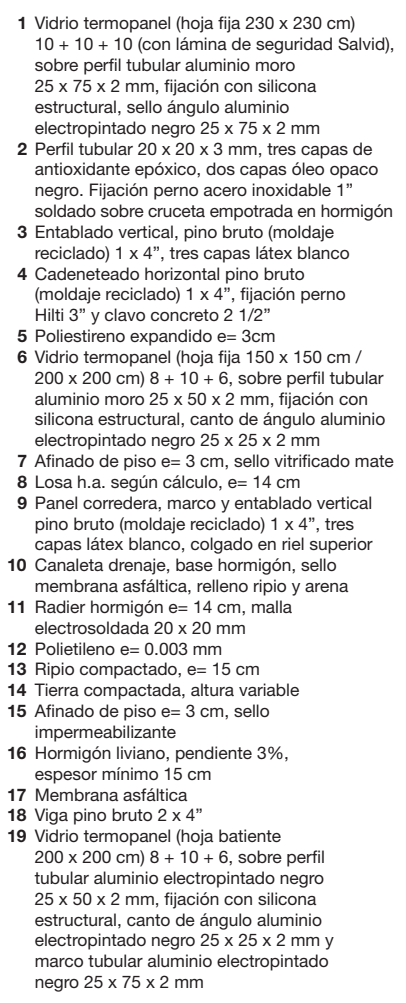

1 Vidrio termopanel (hoja fija $230 \times 230 \mathrm{~cm}$ )
$10+10+10$ (con lámina de seguridad Salvid), sobre perfil tubular aluminio moro estructural, sello ángulo aluminio Perfil tubular $20 \times 20 \times 3 \mathrm{~mm}$, tres capas de soldado sobre cruceta empotrada en hormigón (moldaje

Cadeneteado horizontal pino bruto

Poliestireno expandido (ectropintado negro $25 \times 25 \times 2 \mathrm{~mm}$ osa $\mathrm{c}$ de caps látex (moldajer 10 Canaleta drenaje, base hormigón, sello 11 Radier ho aśán negro $25 \times 75 \times 2 \mathrm{~mm}$

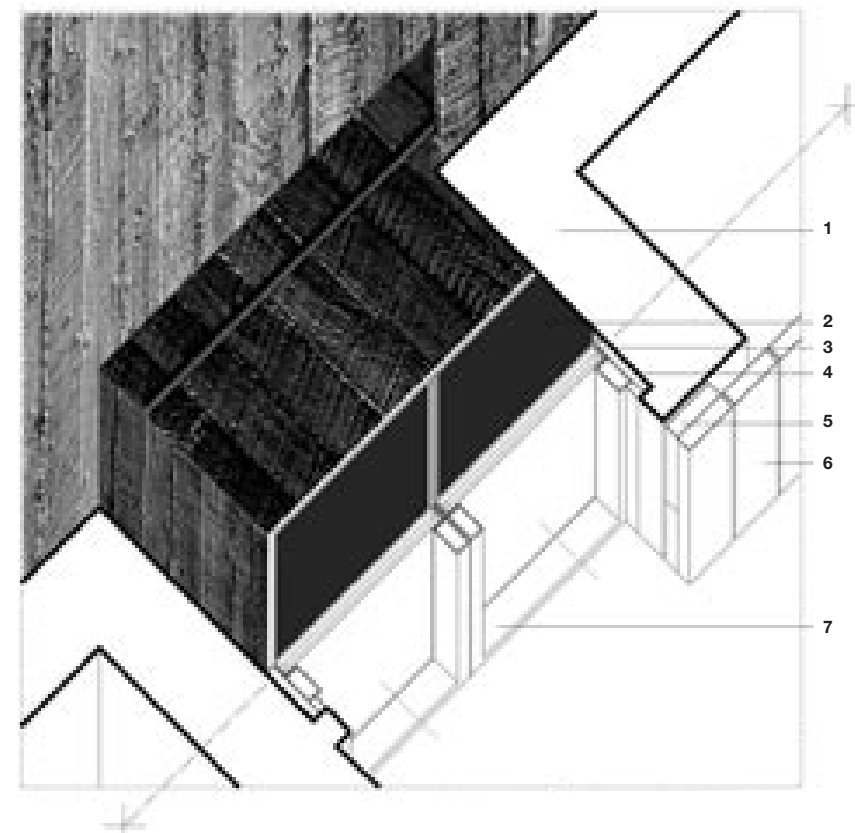

Detalle ventana batiente $200 \times 200 \mathrm{~cm}$

Muro hormigón armado

$\mathrm{e}=15 \mathrm{~cm}$ sg. cálculo, con aditivo hidrófugo y sello interior

2 Vidrio termopanel (hoja batient
$100 \times 200 \mathrm{~cm}) 8+10+6$,

$100 \times 200 \mathrm{~cm}) 8+10+6$,

3 Ángulo aluminio electropintado negro

$25 \times 25 \times 2 \mathrm{~mm}$, remache pop

electropintado negro $25 \times 75 \times 2 \mathrm{~mm}$

5 Marco postigo corredera pino en bruto, $1 \times 4$ " pintado látex blanco

Entablado pino en bruto (moldaje

7 Hoja batiente perfil tubular aluminio

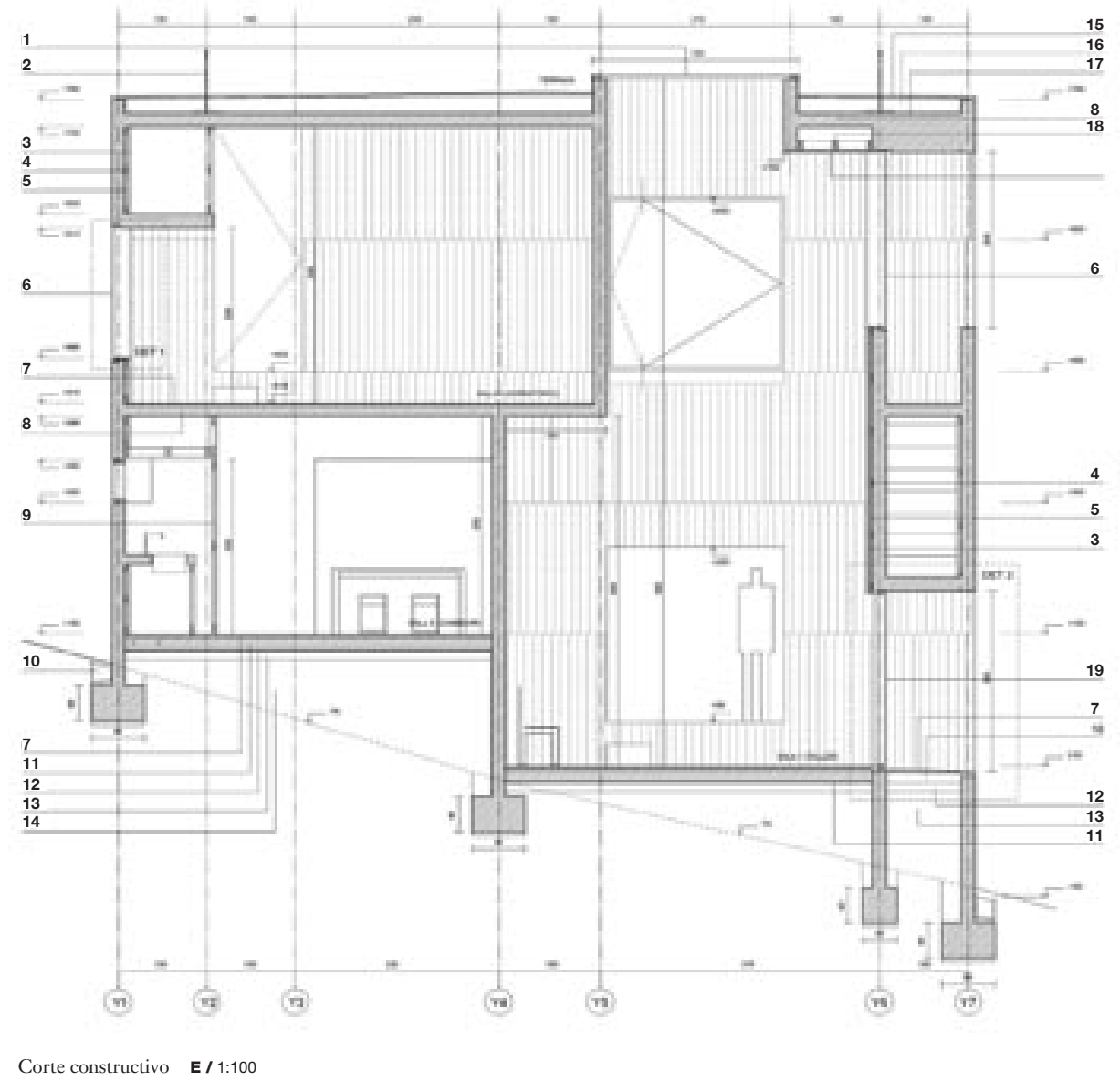

\section{Casa Poli}

Arquitectos Mauricio Pezo, Sofía von Ellrichshausen -

PVE arquitectos

Ubicación Calle Rapa Nui 1, Península de Coliumo, Tomé, Chile Cliente Centro Cultural Casa Poli

Cálculo estructural Cecilia Poblete

Construcción PvE arquitectos

Carpinteros César Manríquez, Roberto Ulloa, Andrés Reyes

Ayudantes Gumercindo Moscoso, Mauricio Cortés, Misuel Cortés Instalaciones sanitarias PvE arquitectos
Proyecto eléctrico Alberto Silva, Claudio Mora, PvE arquitectos Materialidad hormizón armado, madera de pino reciclada aluminio electropintado, vidrio termopanel Presupuesto 13 UF/ m² (US\$379/ m²) Superficie terreno $10.000 \mathrm{~m}^{2}$ Superficie construida $180 \mathrm{~m}^{2}$ Año proyecto 2002 - 2003 Año construcción 2003 - 2005 Fotografía Ana Crovetto (construcción), PvE arquitectos, Cristóbal Palma 